Subscriber access provided by King Abdullah University of Science and Technology Library

\title{
Article
}

\section{Octazethrene and Its Isomer with Different Diradical Characters and Chemical Reactivity: The Role of the Bridge Structure}

Pan Hu, Sangsu Lee, Kyu Hyung Park, Soumyajit Das, Tun Seng Herng, Théo P. Gonçalves, Kuo-Wei Huang, Jun Ding, Dongho Kim, and Jishan Wu

J. Org. Chem., Just Accepted Manuscript • DOI: 10.1021/acs.joc.6b00172 • Publication Date (Web): 11 Mar 2016

Downloaded from http://pubs.acs.org on March 15, 2016

\section{Just Accepted}

"Just Accepted" manuscripts have been peer-reviewed and accepted for publication. They are posted online prior to technical editing, formatting for publication and author proofing. The American Chemical Society provides "Just Accepted" as a free service to the research community to expedite the dissemination of scientific material as soon as possible after acceptance. "Just Accepted" manuscripts appear in full in PDF format accompanied by an HTML abstract. "Just Accepted" manuscripts have been fully peer reviewed, but should not be considered the official version of record. They are accessible to all readers and citable by the Digital Object Identifier (DOI®). "Just Accepted" is an optional service offered to authors. Therefore, the "Just Accepted" Web site may not include all articles that will be published in the journal. After a manuscript is technically edited and formatted, it will be removed from the "Just Accepted" Web site and published as an ASAP article. Note that technical editing may introduce minor changes to the manuscript text and/or graphics which could affect content, and all legal disclaimers and ethical guidelines that apply to the journal pertain. ACS cannot be held responsible for errors or consequences arising from the use of information contained in these "Just Accepted" manuscripts. 


\title{
Octazethrene and Its Isomer with Different Diradical Charac- ters and Chemical Reactivity: The Role of the Bridge Struc- ture
}

Pan Hu, ${ }^{\mathrm{a}}$ Sangsu Lee, ${ }^{\mathrm{b}}$ Kyu Hyung Park, ${ }^{\mathrm{b}}$ Soumyajit Das, ${ }^{\mathrm{a}}$ Tun Seng Herng, ${ }^{\mathrm{c}}$ Théo P. Gonçalves, ${ }^{\mathrm{d}}$ KuoWei Huang, Jun Ding, *, ${ }^{, \mathrm{c}}$ Dongho Kim, ${ }^{, \mathrm{b}}$ and Jishan $\mathrm{Wu}^{*, \mathrm{a}}$

${ }^{\mathrm{a}}$ Department of Chemistry, National University of Singapore, 3 Science Drive 3, 117543, Singapore

${ }^{\mathrm{b}}$ Spectroscopy Laboratory for Functional $\pi$-Electronic Systems and Department of Chemistry, Yonsei University, Seoul 120749 , Korea

${ }^{\mathrm{c}}$ Department of Materials Science \& Engineering, National University of Singapore, 119260, Singapore

${ }^{\mathrm{d} D i v i s i o n}$ of Physical Science and Engineering and KAUST Catalysis Center, King Abdullah University of Science and Technology (KAUST), Thuwal 23955-6900, Kingdom of Saudi Arabia

\section{GRAPHICAL ABSTRACT}

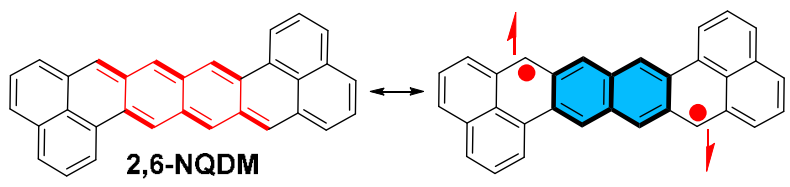

VS

Relatively stable, $y_{0}=0.35$

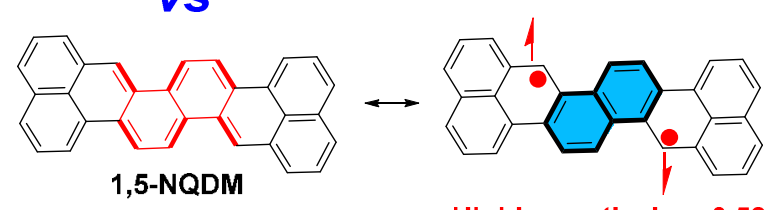

Highly reactive! $y_{0}=0.58$

\begin{abstract}
The fundamental relationship between structure and diradical character is important for the development of open-shell diradicaloid-based materials. In this work, we synthesized two structural isomers bearing a 2,6-naphthoquinodimethane or a 1,5naphthoquinodimethane bridge and demonstrated that their diradical characters and chemical reactivity are quite different. The mesityl or pentafluorophenyl substituted octazethrene derivatives OZ-M/OZ-F and their isomer OZI-M (with mesityl substituents) were synthesized via an intramolecular Friedel-Crafts alkylation followed by oxidative dehydrogenation strategy from the key building blocks 4 and 11. Our detailed experimental and theoretical studies showed that both isomers have an open-shell singlet ground state with a remarkable diradical character $\left(y_{0}=0.35\right.$ and 0.34 for $\mathbf{O Z - M}$ and $\mathbf{O Z - F}$, and $y_{0}=0.58$ for $\left.\mathbf{O Z I - M}\right)$. Compounds OZ-M and OZ-F have good stability under the ambient environment while OZI-M has high reactivity and can be easily oxidized to a dioxo-product 15, which can be correlated to their different diradical characters. Additionally, we investigated the physical properties of OZ-M, OZ-F and 15.
\end{abstract}




\section{INTRODUCTION}

Open-shell $\pi$-conjugated polycyclic hydrocarbons (PHs) have recently attracted tremendous interest due to their unique electronic, optical and magnetic properties applicable to organic electronics, non-linear optics, spintronics, and energy storage devices. ${ }^{1}$ So far, thanks to the development of efficient stabilizing strategy and synthetic method, several types of stable open-shell PHs with a singlet diradical ground state have been reported, which include indenofluorenes, ${ }^{2}$ bisphenalenyls, ${ }^{3}$ zethrenes, ${ }^{4}$ anthenes, ${ }^{5}$ and quinoidal rylenes. ${ }^{6}$ Most of the reported open-shell molecules contain a pro-aromatic quinodimethane (QDM), naphthoquinodimethane (NQDM) or anthraquinodimethane (AQDM) substructure, which can recover their aromaticity in the diradical form and serve as the major driving force to be a diradical in the ground state. Recently, there is an arising interest to study the chemical and physical properties of different structural isomers. For example, Tobe and Haley et al. reported several indenofluorene isomers by embedding three types of QDM units ( $p$-QDM, $o$-QDM and $m$-QDM) in the aromatic hydrocarbon framework (Figure 1a) ${ }^{2 a, 2 b, 2 f}$ Interestingly, the diradical characters and the reactivity are quite different from each other, which can be correlated to the number of aromatic sextet rings gained from the closed-shell to the diradical resonance forms. ${ }^{7}$ Our group reported that a $p$-QDM bridged heptazethrene (HZ) has an open-shell singlet diradical ground state, ${ }^{4 \mathrm{~b}, 4 \mathrm{c}}$ while the $m$-QDM bridged isomer $m$-HZ has a triplet biradical ground state because no Kekulé structure can be drawn for this molecule (Figure $1 \mathrm{~b}$ ). ${ }^{8}$ However, there are rare discussions on the physical properties and chemical reactivity of other isomers containing a higher order quinodimethane substructure. Herein, two naphthoquinodimethane isomers, the 2,6- naphthoquinodimethane (2,6-NQDM) and 1,5naphthoquinodimethane (1,5-NQDM) will be investigated. These two molecules can be depicted as resonance of a quinoidal form and a diradical form with recovery of an aromatic naphthalene ring (Figure 1d). More informative diradical character index $y_{0}$ of 2,6-NQDM and 1,5-NQDM was calculated (UCAM-B3LYP/6-31G(d,p) method) to be 0.01 and 0.33 , respectively $\left(y_{0}\right.$ is derivated from the occupation number of the lowest unoccupied natural orbital in the ground state, $0<y_{0}<1,0$ representing closed-shell state and 1 representing a pure diradical state). There are a few reports on the 2,6-NQDM based singlet diradicaloids such as the extended diphenalenenoindacene, ${ }^{3 \mathrm{~d}}$ indenofluorene ${ }^{2 \mathrm{e}}$ and octazethrene. ${ }^{4 \mathrm{~b}}$ However, to the best of our knowledge, there is no report on the 1,5-NQDM congeners. Our particular interest here is to synthesize and study the properties of two isomers, the 2,6-NQDM bridged octazethrene and the 1,5-NQDM bridged octazethrene (Figure 1c and d). Both isomers should have an open-shell singlet diradical ground state due to the recovery of an aromatic naphthalene ring in the diradical form, and the major difference is that the first isomer contains two fused $p$-QDM units, while the second isomer has two fused $o$-QDM units. Thus it is interesting to study which isomer has a larger diradical character and how this difference affects their chemical reactivity and physical properties. To stabilize the reactive species, it is necessary to introduce bulky mesityl or electron-deficient pentafluorophenyl substituents to block the most reactive sites (Figure 1d). At the same time, the hexyloxy groups are attached to the two terminal naphthalene units to control the regio-selective reaction and to improve the solubility. 
(a)<smiles></smiles><smiles></smiles><smiles></smiles>

(b)

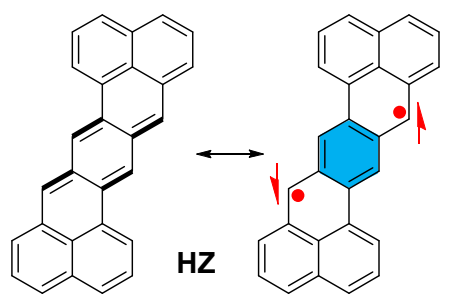

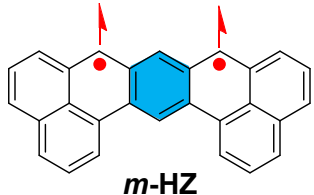

(c)

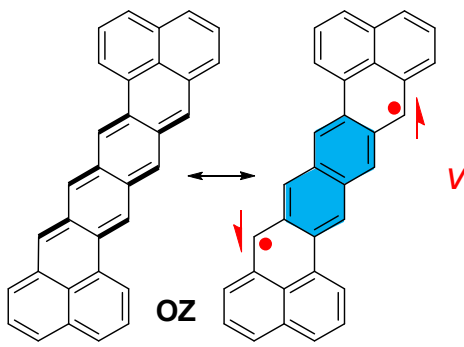

VS

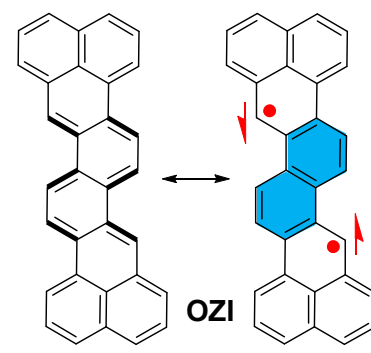

(d)

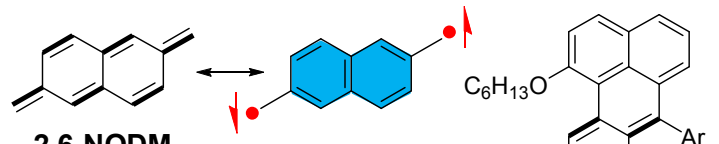

2,6-NQDM

VS

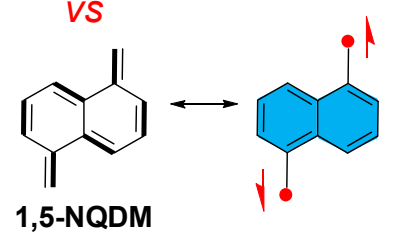

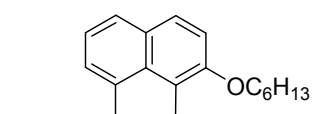

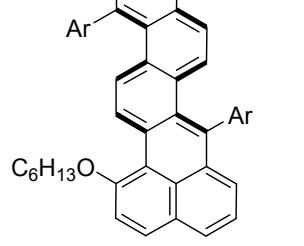

OZ-M $(A r=$ Mesityl) OZ-F $\left(\mathrm{Ar}=\mathrm{F}_{5} \mathrm{Ph}\right)$
OZI-M (Ar = Mesityl)

OZI-F $\left(\mathrm{Ar}=\mathrm{F}_{5} \mathrm{Ph}\right)$

Figure 1. (a) Three indenofluorene isomers; (b) heptazethrene and its isomer; (c) octazethrene and its isomer; (d) structures of 2,6NQDM and 1,5-NQDM, and the four targeted molecules.

\section{RESULTS AND DISCUSSION}

Synthesis. Previously, we reported that the triisopropylsilyl ethynyl (TIPS) substituted octazethrene analogue OZ-TIPS could be synthesized via a two-step route which involves a nucleophilic addition of the diketone precursor with organolithium regent, followed by reduction with $\mathrm{SnCl}_{2}{ }^{4 \mathrm{c}}$ However, there are some limitations of this method: 1) the synthesis and purification of the octazethrene diketone intermediate is tedious and the yield is very low; 2) due to the poor solubility of the octazethrene diketone intermediate, the yield of the addition step is low; and 3) it is hard to introduce other substituents (e.g. aryl) to the bay region due to the undesirable Michael addition side reaction. Herein, we report a much more efficient alternative method to synthesize the mesityl and pentafluorophenyl substituted octazethrene derivatives (OZ-M and OZ-F, respectively) and similar strategy can be applied to the synthesis of the octazethrene isomers (OZI-M and OZI-F) (Scheme 1). The key building blocks are the naphthalene derivatives 
$\mathbf{4}$ and $\mathbf{1 1}$ carrying two triflate and two aldehyde groups at different positions. The synthesis commenced from the protection of hydroxyl group of 3,7-dibromo-naphthalene-2,6-diol 1 by MOM group to give $\mathbf{2}$ in $90 \%$ yield. Compound $\mathbf{2}$ was treated with $n$ BuLi followed by addition of anhydrous DMF to afford the dialdehyde 3 in $65 \%$ yield. The key building block compound 4 was then obtained in $85 \%$ overall yield by removal of MOM protective groups in $\mathbf{3}$ followed by reaction with trifluoromethanesulfonic anhydride. Suzuki coupling reaction between $\mathbf{4}$ and (2-(hexyloxy)naphthalen-1-yl)boronic acid $\mathbf{9}$ afforded $\mathbf{5}$ in $90 \%$ yield. The alkoxy chain was introduced to improve the solubility and prevent the formation of a five-membered ring containing isomer. Then, compound 5 was treated with mesitylmagnesium bromide or pentafluorophenylmagnesium bromide to give the corresponding diol 6a or $\mathbf{6 b}$, which was subjected to a $\mathrm{BF}_{3} \cdot \mathrm{OEt}_{2}$ mediated Friedel-Crafts alkylation reaction to give the dihydro- precursor $7 \mathbf{a}$ or $7 \mathbf{b}$. Compounds OZ-M and OZ-F were finally obtained as black solids by oxidative dehydrogenation of 7a/7b with DDQ. The

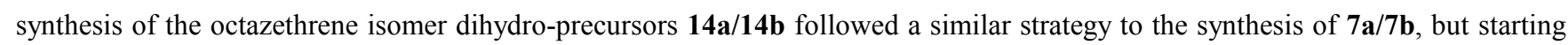
from the 1,5-dibromonaphthalene-2,6-diol (8) (Scheme 1). The dehydrogenation of precursor 14a was conducted by treatment with DDQ in dry toluene at room temperature. However, this gave a quite reactive species (OZI-M) which was transformed into the dioxo- compound 15 (dark red solid) in one hour. Workup and purification in air afforded compound $\mathbf{1 5}$ in $35 \%$ yield. However, the pentafluorophenyl substituted precursor 14b cannot be dehydrogenated by DDQ even under reflux in toluene. The structures of compounds OZ-M, OZ-F and 15 were unambiguously identified by NMR, high-resolution mass spectrometry and X-ray crystallographic analysis (vide infra and SI). 
Ground states of OZ-M and OZ-F. Compounds OZ-M and OZ-F were experimentally identified to have an open-shell singlet diradical ground state by magnetic measurements. The solutions of $\mathbf{O Z - M}$ and $\mathbf{O Z - F}$ in $d_{8}$-toluene show broadened NMR signals at high temperature and the spectra become sharper at lower temperature (Figure S1 in SI), which is typical phenomenon for the singlet diradicaloids. The powders of OZ-M and OZ-F exhibit a broad electron spin resonance (ESR) spectrum at $g_{\mathrm{e}}=2.0027$ and $g_{\mathrm{e}}=2.0029$, respectively (Figure 2a, c), and the signal intensity decreases as temperature decreases, again implying a singlet ground state for both compounds. The superconducting quantum interference device (SQUID) measurements further confirmed their 
singlet ground states as the magnetic susceptibility increases with increase of temperature after $250 \mathrm{~K}$, correlating to a thermal population from singlet to paramagnetic triplet state (Figure $2 \mathrm{~b}, \mathrm{~d}$ ). The singlet-triplet energy gap $\left(\Delta E_{\mathrm{S}-\mathrm{T}}\right)$ was estimated to be 1915.7 K (-3.81 kcal/mol) for OZ-M and $-1980 \mathrm{~K}(-3.93 \mathrm{kcal} / \mathrm{mol})$ for compound OZ-F by a careful fitting of the data using the Bleaney-Bowers equation. ${ }^{10}$
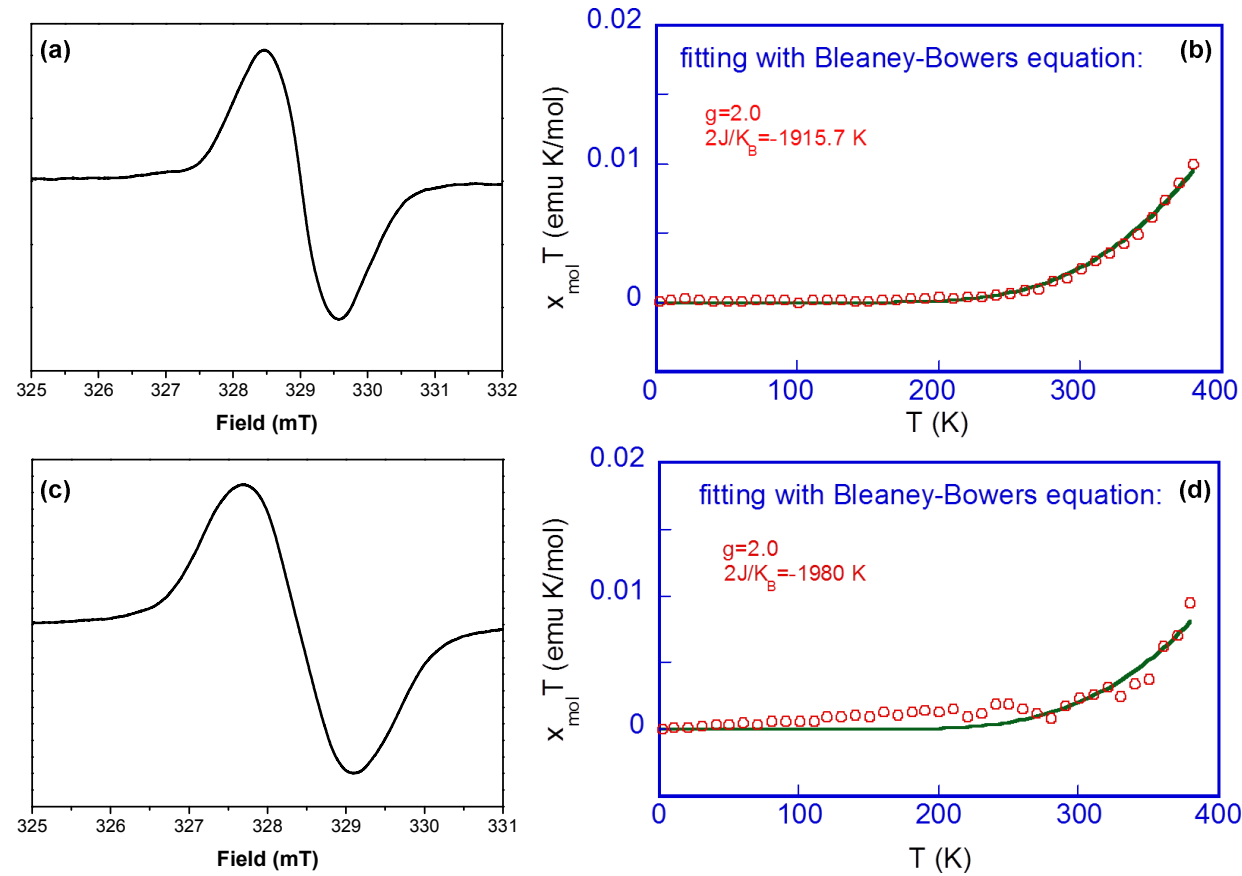

Figure 2. Left: ESR spectrum of compounds (a) OZ-M and (c) OZ-F in powder measured at room temperature. Right: $\chi T-T$ plot for the solid samples of (b) OZ-M and (d) OZ-F in SQUID measurements. The measured data were plotted as open circles, and the fitting curve was drawn using Bleaney-Bowers equation with $g_{\mathrm{e}}=2.00$.

Single crystals suitable for X-ray crystallographic analysis were obtained for OZ-M and OZ-F by solvent diffusion method and their structures are shown in Figure 3. ${ }^{11}$ Both molecules are slightly deviated from planarity due to the steric hindrance between the aryl/alkoxyl groups and the main $\pi$-conjugated framework, with a torsional angle of $8.4^{\circ}$ for $\mathbf{O Z}-\mathbf{M}$ and $6.0^{\circ}$ for $\mathbf{O Z}-\mathbf{F}$. The mesityl and the pentafluorophenyl groups are nearly perpendicular to the octazethrene backbone, with a dihedral angle of $89^{\circ}$ and $72^{\circ}$, respectively (Figure 3a,c). Both molecules are packed into a one-dimensional polymeric chain structure via intermolecular $\pi-\pi$ (or spin-spin) interactions (Figure 3b,d). Significant $\pi$-surface overlap was observed in OZ-M, with an average $\pi$-stacking distance of $3.424 \AA$. Similar observation was found in Kubo's bis(phenalenyl) molecule with even smaller $\pi$-stacking distance of $3.137 \AA .^{3 e}$ In OZ-F, there is almost no overlap between the octazethrene $\pi$-surfaces, but close contacts between the edge carbon atoms with a short distance of $3.266 \AA$ was observed, which may imply moderate intermolecular spin-spin interactions. 
(a)

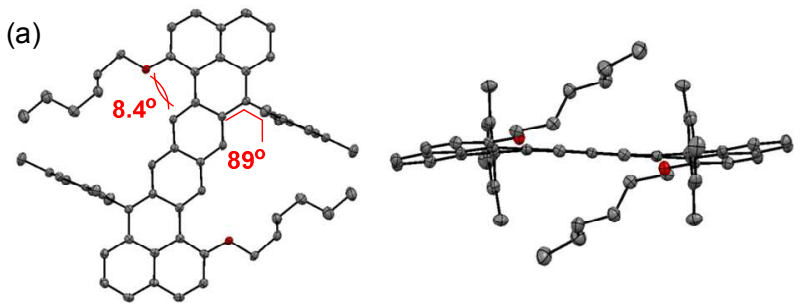

(b)
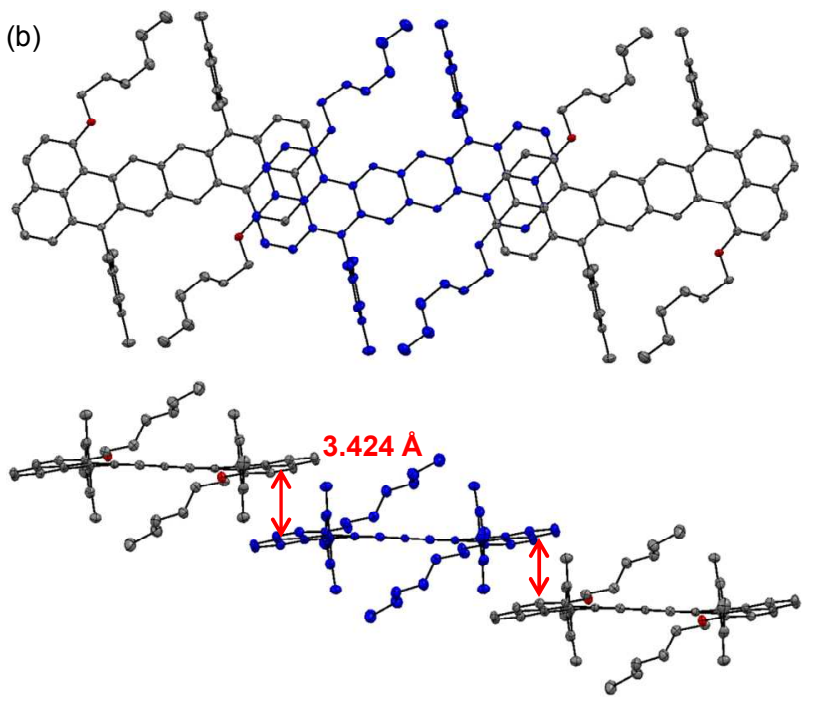

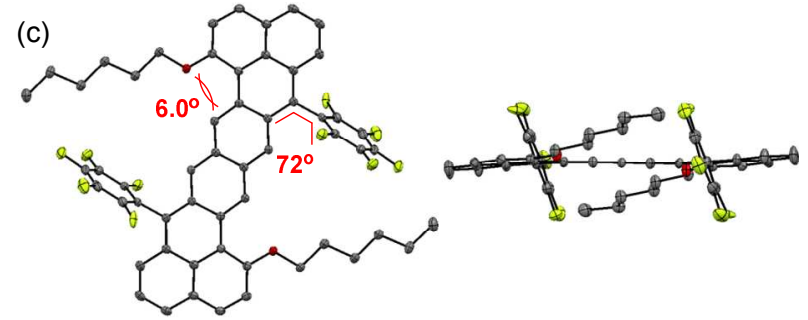

(d)
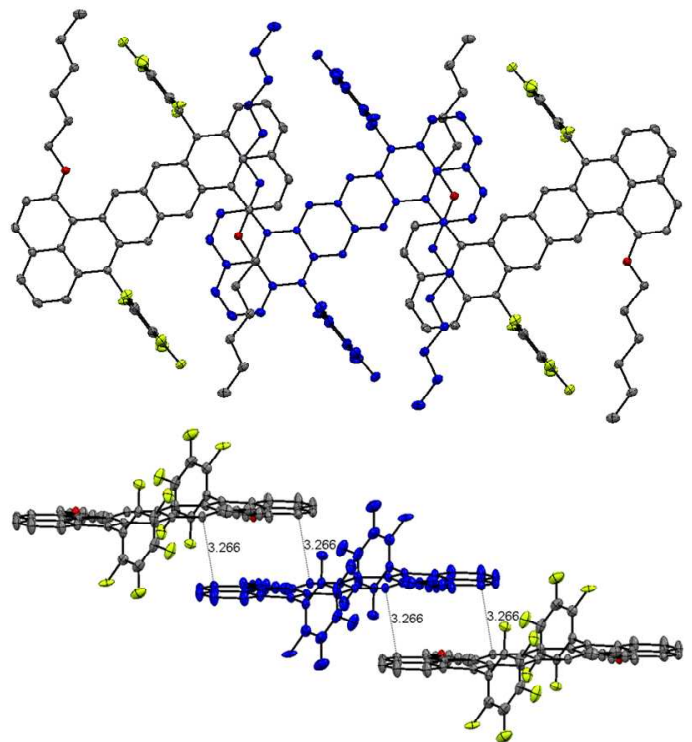

Figure 3. ORTEP drawings of the single-crystal structures of (a) OZ-M and (c) OZ-F and (b, d) their 3D packing structures, each with a top view and a side view. Solvent molecules and hydrogen atoms are omitted for clarity.

Both OZ-M and OZ-F exhibit obvious bond alternation in the central 2,6-NQDM framework (Figure 4a and Figure S2 in SI). However, the exo-methylene double bonds (bond $a$ ) in OZ-M $(1.388 \AA)$ and OZ-F (1.392 $\AA$ ) are much longer than the double bond in olefins (1.33-1.34 $\AA$ ), indicating remarkable contribution of the diradical resonance form to the ground state electronic structure. The calculated nucleus independent chemical shift $(\mathrm{NICS}(1) \mathrm{zz})^{12}$ values of molecule OZ-M displayed remarkable aromatic character for the central benzene ring A (-11.2 ppm) and two terminal naphthalene units (rings C: -20.4 ppm and ring D: $15.2 \mathrm{ppm}$ ), indicating a great contribution from the diradical resonance form. NICS(1)zz calculations of molecule OZ-F show similar result, with $-10.4,-20.5$ and $-15.2 \mathrm{ppm}$, for rings A, C and D, respectively. Broken symmetry DFT calculations (UCAMB3LYP/6-31G(d,p)) also predict that the energy of the singlet biradical (SB) state is 5.8 and $9.4 \mathrm{kcal} / \mathrm{mol}$ lower than that of the triplet biradical (TB) and closed-shell (CS) states, respectively, for OZ-M, while the energy of the SB state is 5.7 and $10.8 \mathrm{kcal} / \mathrm{mol}$ lower than those of the TB and CS states, respectively, for OZ-F. Therefore, both molecules feature a singlet diradical ground state. Diradical character index $y_{0}$ of $\mathbf{O Z - M}$ and $\mathbf{O Z - F}$ was calculated to be 0.35 and 0.34 , respectively. These theoretical calculations are in good agreement with the magnetic observations. In accord with the moderate diradical character, the calculated singly occupied 
molecular orbital (SOMO) profiles of the $\alpha$ and $\beta$ spin of both molecules showed disjoint feature (Figure S3 in SI). The spin densities are evenly distributed throughout the whole octazethrene framework and even to the mesityl and pentafluorophenyl substituents (Figure 4b), explaining the good stabilities of both compounds. For comparison, OZ-TIPS was calculated to have a larger diradical character $\left(y_{0}=0.434\right)$ and smaller singlet-triplet energy gap $\left(\Delta E_{\mathrm{S}-\mathrm{T}}=-4.4 \mathrm{kcal} / \mathrm{mol}\right)$ due to more effective conjugation between the TIPS groups and the octazethrene framework. ${ }^{4 \mathrm{c}}$
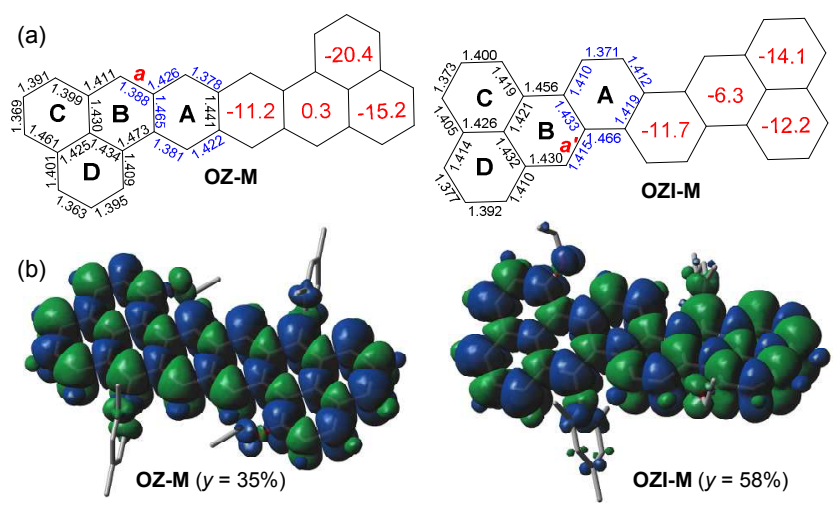

Figure 4. (a) Mean values of bond length $(\AA)$ (from crystallographic structure for $\mathbf{O Z}-\mathbf{M}$, and from calculation for OZI-M) and calculated NICS(1)zz values (red numbers in the hexagons) in the molecular backbone. (b) Calculated (UCAM-B3LYP) spin density distribution of the singlet diradicals of OZ-M and OZI-M. To simplify calculation, the hexyloxy group are replaced by the ethoxy group.

Ground state of OZI-M. As can be seen from Figure 1, molecule OZI-M could show significant diradical character due to the recovery of the central aromatic naphthalene ring, similar to OZ-M. DFT calculations (UCAM-B3LYP/6-31G(d,p)) show that the energy of its SB state is 2.1 and $11.8 \mathrm{kcal} / \mathrm{mol}$ lower than the TB and closed-shell states, therefore, also identifying an open-shell singlet ground state. However, the calculated $\Delta E_{\mathrm{S}-\mathrm{T}}$ value $(-2.1 \mathrm{kcal} / \mathrm{mol})$ of $\mathbf{O Z I - M}$ is much smaller than those for $\mathbf{O Z}-\mathbf{M}$ and $\mathbf{O Z}-$ $\mathbf{F}$, as a result, OZI-M has a much larger diradical character $\left(y_{0}=0.58\right)$. The calculated SOMO profiles of the $\alpha$ and $\beta$ spin of OZIM showed similar disjoint feature, and the spin densities are distributed throughout the whole $\pi$-conjugated backbone (Figure $4 \mathrm{~b}$ and Figure S3 in SI). Due to the existence of steric repulsion between the mesityl and alkoxy substituents with the central naphthalene unit, the calculated geometry of OZI-M displays a twisted structure (Figure 4b and Figure S3 in SI). Bond length analysis on the central 1,5-NQDM unit in OZI-M shows that the extra methylene double bond (bond $\left.a^{\prime}\right)$ is much longer (1.415 $\AA$ ) than the bond $a$ in OZ-M, implying a larger diradical character (Figure 4a). The NICS(1)zz values of OZI-M display comparable aromatic character for the central benzene ring (ring A: -11.7 ppm) and two terminal naphthalene units (ring C: -12.2 and ring D: $14.1 \mathrm{ppm})$. The bridging ring B shows negative NICS(1)zz value $(-6.3 \mathrm{ppm})$ while the corresponding ring B in OZ-M has a near zero NICS(1)zz value (0.3 ppm), again, indicating that OZI-M has a larger contribution of the diradical resonance form. The larger 
diradical character and the existence of larger strain in OZI-M make it more reactive than OZ-M, as we observed experimentally. Indeed, the in situ generated OZI-M is highly reactive and only the dioxo- product $\mathbf{1 5}$ was isolated, which was identified by X-ray crystallographic analysis. ${ }^{13}$ Molecule $\mathbf{1 5}$ has a twisted structure with a large torsional angle of $18.3^{\circ}$ and bond length analysis reveals a fused anthracene dimer structure annulated with two $\alpha, \beta$-unsaturated ketone units (Figure 5). Compared to the desired compound OZI-M, the hexyl groups are kicked off and two ketone groups are formed, meanwhile with recovery of two fused anthracene rings. This unusual reaction could be explained by the large spin density $(0.23)$ at the carbon atoms linked with the hexyloxy chains (Figure S4 in SI). The OZI-M is so reactive that it cannot be directly determined by in situ ESR measurement during the dehydrogenation reaction. An intense single-line ESR signal $\left(g_{\mathrm{e}}=2.00273\right)$ was observed after adding the DDQ in 15 minutes (Figure $\mathrm{S} 5$ in $\mathrm{SI}$ ) and the spin concentration was determined to be about $63.5 \%$ by using DPPH as standard under the same concentration and the same measurement conditions. The variable temperature (VT) ESR measurements on the solid sample after removing the solvent under nitrogen showed that the ESR intensity $(I)$ increased with decreasing temperature $(T)$, with $I$ being approximately proportional to $1 / T$ (Figure $\mathrm{S} 5$ in $\mathrm{SI}$ ), indicating that the major magnetically active species in the mixture is a monoradical intermediate rather than the diradical, which may be due to the high reactivity and the short life time of OZI-M.

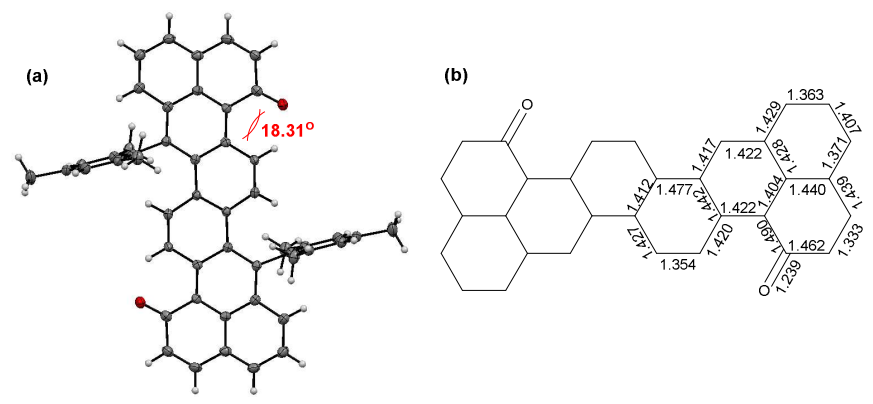

Figure 5. (a) ORTEP drawing of the crystallographic structure of 15; (b) mean bond lengths ( $\AA$ ) of the backbone.

Optical and electrochemical properties. Compound OZ-M in dichloromethane (DCM) solution displays a well resolved spectrum in the UV-vis-NIR region with an intense absorption at $649 \mathrm{~nm}(\varepsilon=8.7 \times 104 \mathrm{M}-1 \mathrm{~cm}-1)$ and two weak bands at 692 $\mathrm{nm}$ and $757 \mathrm{~nm}$ (Figure 6a and Table 1). The band shape is similar to those for many reported diradicaloids ${ }^{4-6}$ and the weak absorption bands in the low-energy region originate from the presence of a low-lying singlet excited state dominated by a doubly excited electronic configuration $(\mathrm{H}, \mathrm{H} \rightarrow \mathrm{L}, \mathrm{L}) .{ }^{14}$ Compound $\mathbf{O Z}-\mathbf{F}$ with a different substituent group at the bay region shows almost the same absorption spectrum to that of OZ-M (Figure S6 in SI). However, compared with the OZ-TIPS, ${ }^{4 b}$ the lowest energy absorption maximum of OZ-M or OZ-F is blue shifted about $38 \mathrm{~nm}$ due to the less effective conjugation between the octazethrene backbone and the mesityl/phenyl substituents. Compound $\mathbf{1 5}$ exhibits a very different absorption spectrum, with a broad band between 450 and $600 \mathrm{~nm}$ and a weak absorption tail up to $750 \mathrm{~nm}$ (Figure $6 \mathrm{~b}$ and Table 1). This long absorption tail might be affected by the intramolecular charge transfer due to the existence of two ketone groups. 

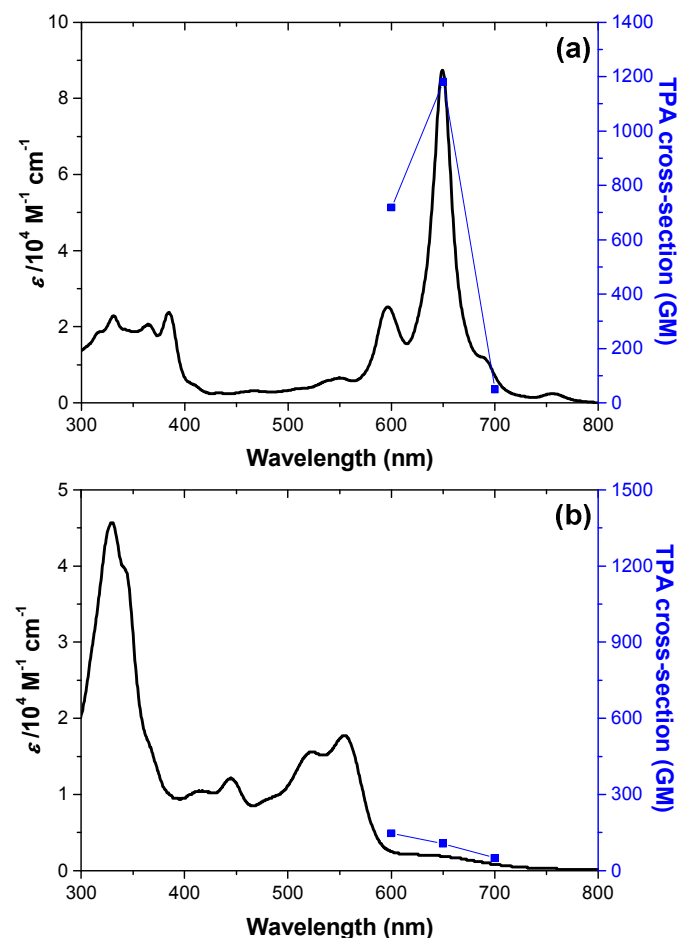

Figure 6. One-photon and two-photon absorption spectra of (a) OZ-M and (b) 15 recorded in toluene. TPA spectra are plotted at $\lambda_{\mathrm{ex}} / 2$.

Table 1. Photophysical and electrochemical data of the compounds OZ-M, OZ-F, and 15.

\begin{tabular}{|c|c|c|c|c|c|c|c|c|c|c|}
\hline & $\begin{array}{l}\lambda_{\max } \\
(\mathrm{nm})\end{array}$ & $\begin{array}{c}\varepsilon_{\max } \\
\left(\mathrm{M}^{-1} \mathrm{~cm}^{-1}\right)\end{array}$ & $\begin{array}{l}E_{\mathrm{ox}}^{1 / 2} \\
(\mathrm{~V})\end{array}$ & $\begin{array}{c}E_{\mathrm{red}}^{1 / 2} \\
(\mathrm{~V})\end{array}$ & $\begin{array}{c}\text { HOMO } \\
(\mathrm{eV})\end{array}$ & $\begin{array}{c}\text { LUMO } \\
(\mathrm{eV})\end{array}$ & $\begin{array}{l}E_{\mathrm{g}}^{E C} \\
(\mathrm{eV})\end{array}$ & $\begin{array}{l}E_{\mathrm{g}}^{\text {opt }} \\
(\mathrm{eV})\end{array}$ & $\begin{array}{c}\tau \\
(\mathrm{ps})\end{array}$ & $\begin{array}{l}\sigma^{(2)}{ }_{\text {max }} \\
(\mathrm{GM})\end{array}$ \\
\hline OZ-M & $\begin{array}{l}595 \\
648 \\
692 \\
757\end{array}$ & $\begin{array}{c}25110 \\
87420 \\
11470 \\
2450\end{array}$ & $\begin{array}{l}0.30 \\
0.09\end{array}$ & -1.82 & -4.44 & -3.09 & 1.35 & 1.56 & 2300 & $\begin{array}{c}1200 \\
(1300 \mathrm{~nm})\end{array}$ \\
\hline OZ-F & $\begin{array}{l}596 \\
649 \\
688 \\
754\end{array}$ & $\begin{array}{c}19140 \\
63770 \\
12230 \\
2130\end{array}$ & $\begin{array}{l}0.01 \\
0.28\end{array}$ & $\begin{array}{l}-1.88 \\
-1.52\end{array}$ & -4.71 & -3.37 & 1.34 & 1.58 & 2400 & $\begin{array}{c}1300 \\
(1300 \mathrm{~nm})\end{array}$ \\
\hline 15 & $\begin{array}{l}328 \\
445 \\
519 \\
554\end{array}$ & $\begin{array}{l}45780 \\
12160 \\
15380 \\
17670\end{array}$ & 0.88 & $\begin{array}{l}-2.32 \\
-1.54 \\
-1.41\end{array}$ & -5.61 & -3.51 & 2.10 & 1.66 & 1200 & $\begin{array}{c}150 \\
(1200 \mathrm{~nm})\end{array}$ \\
\hline
\end{tabular}

$\lambda_{\max }$ : maxium absorption peak wavelength. $\varepsilon_{\max }$ : molar extinction coefficient at the absorption maximum. $E_{\mathrm{ox}}{ }^{1 / 2}$ and $E_{\mathrm{red}}{ }^{1 / 2}$ are half-wave potentials of the oxidative and reductive waves, respectively, with potentials versus $\mathrm{Fc} / \mathrm{Fc}^{+}$couple. HOMO and LUMO energy levels were calculated according to equations: $\mathrm{HOMO}=-\left(4.8+E_{o x}{ }^{\text {onset }}\right) \mathrm{eV}$ and $\mathrm{LUMO}=-\left(4.8+E_{\text {red }}{ }^{\text {onset }}\right) \mathrm{eV}$, where $E_{\mathrm{ox}}{ }^{\text {onset }}$ and $E_{\text {red }}{ }^{\text {onset }}$ are the onset potentials of the first oxidative and reductive redox wave, respectively. $E_{\mathrm{g}}{ }^{E C}$ : electrochemical energy gap derived from LUMO-HOMO. $E_{\mathrm{g}}{ }^{O p t}$ : optical energy gap derived from lowest energy absorption onset in the absorption spectra. $\tau$ : excited lifetime based on the TA measurements. $\sigma_{\text {max }}^{(2)}$ maximum TPA cross section. 
The excited-state dynamics of compounds OZ-M, OZ-F and 15 were investigated by femtosecond transient absorption (TA) measurements. Compounds OZ-M and OZ-F exhibit similar TA spectra with a ground-state bleaching (GSB) signal around 650 $\mathrm{nm}$ as well as two weak excited-state absorption (ESA) bands in the $450-550$ and $700-850 \mathrm{~nm}$ spectral regions (Figure $7 \mathrm{a}$ and Figure S7 in SI). The singlet excited-state lifetimes ( $\tau$ ) of $\mathbf{O Z}-\mathbf{M}$ and $\mathbf{O Z}-\mathbf{F}$ were determined to be 2.3 and 2.4 ns, respectively, which are slightly longer than that of OZ-TIPS $(\tau=1.6 \mathrm{~ns})^{4 \mathrm{e}}$ due to their smaller diradical character. The diketone compound $\mathbf{1 5}$ exhibits intensive GSB signal at 450-700 nm and weak ESA signal at 700-850 nm (Figure 7b). The singlet excited-state lifetime of 15 was estimated to be $1.2 \mathrm{~ns}$.
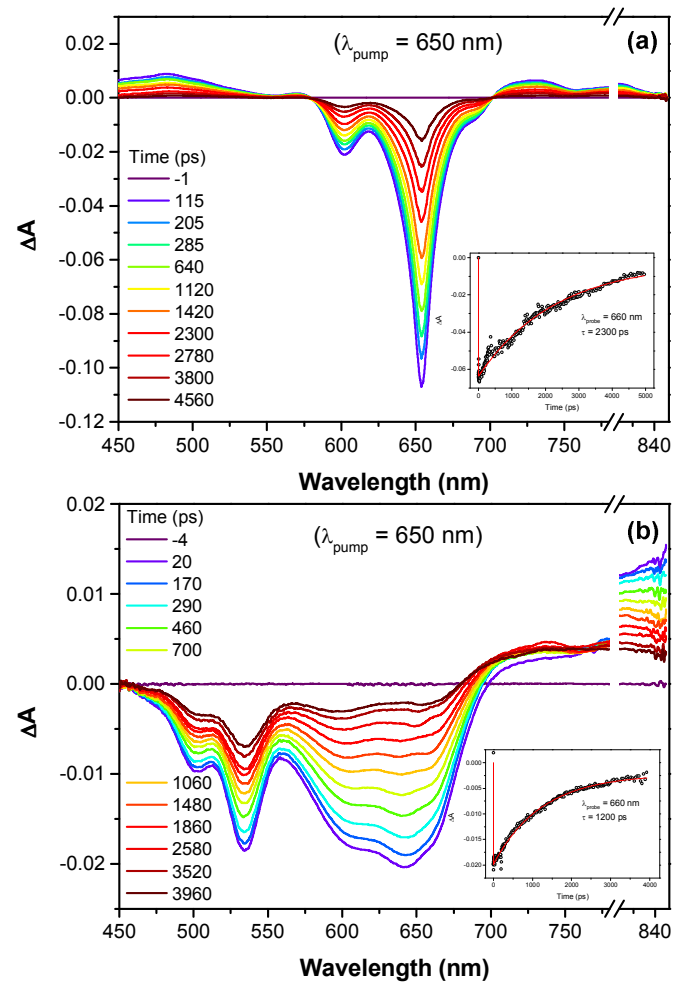

Figure 7. Femtosecond transient absorption spectra of (a) OZ-M and (b) 15 recorded in toluene. Insert are the decay curves.

\begin{abstract}
Recently, many reports demonstrated that molecules with a moderate diradical character would exhibit remarkable hyperpolarizability $\gamma^{4,7,15}$ Therefore, the two-photon absorption (TPA) measurements were conducted for compounds OZ-M and OZ-F by the Z-scan method (refer to the Experimental Section) in the wavelength range from 1200 to $1400 \mathrm{~nm}$, where one-photon absorption contribution is negligible (Figure 6a and Figure S8 in SI). Compound OZ-M exhibits remarkable TPA cross-sections with $\sigma_{\max }^{(2)}=1200 \mathrm{GM}$ at $1300 \mathrm{~nm}$, which is slightly smaller than that of OZ-F $\left(\sigma_{\max }^{(2)}=1300 \mathrm{GM}\right.$ at $\left.1300 \mathrm{~nm}\right)$ and comparable to that of OZ-TIPS $\left(\sigma^{(2)} \max =1200 \mathrm{GM}\right.$ at $\left.1250 \mathrm{~nm}\right) .{ }^{4 \mathrm{~b}}$ Compound 15 exhibits a smaller TPA cross-section $\left(\sigma^{(2)}{ }_{\max }=150 \mathrm{GM}\right.$ at 1200 $\mathrm{nm}$ ) in the wavelength range we measured (Figure $6 \mathrm{~b}$ and Figure $\mathrm{S} 8$ in SI).
\end{abstract}


Cyclic voltammetry and differential pulse voltammetry were conducted to study the electrochemical properties of compounds OZ-M, OZ-F and $\mathbf{1 5}$ (Figure 8, Table 1 and Figure S9 in SI). Compound OZ-M gave two reversible oxidation waves at $E_{\mathrm{ox}}{ }^{1 / 2}=-0.30,0.09 \mathrm{~V}$ and one quasi-reversible reduction waves at $E_{\mathrm{red}}{ }^{1 / 2}=-1.82 \mathrm{~V}\left(v s \mathrm{Fc} / \mathrm{Fc}^{+}, \mathrm{Fc}=\right.$ ferrocene $)$, while compound OZ-F showed two reversible oxidation waves at $E_{\mathrm{ox}}{ }^{1 / 2}=-0.01,0.28 \mathrm{~V}$ and two reversible reduction waves at $E_{\mathrm{red}}{ }^{1 / 2}$ $=-1.52$ and $-1.88 \mathrm{~V}$. The electrochemical energy gaps were determined as 1.35 and $1.34 \mathrm{eV}$ for $\mathbf{O Z}-\mathbf{M}$ and $\mathbf{O Z}-\mathbf{F}$, respectively, which are consistent with their optical energy band gap (Table 1). It is worth noting that due to the electronwithdrawing pentafluorophenyl substituents, both the HOMO and LUMO of OZ-F are lowered in comparison to those of OZ-M (Table 1), leading to more reversible reduction waves. Compound $\mathbf{1 5}$ showed three reduction waves with $E_{\text {red }}^{1 / 2}=$ $-1.41,-1.54$ and $-2.32 \mathrm{~V}$ due to the electron-withdrawing character of the ketone groups, and it is hard to be oxidized.

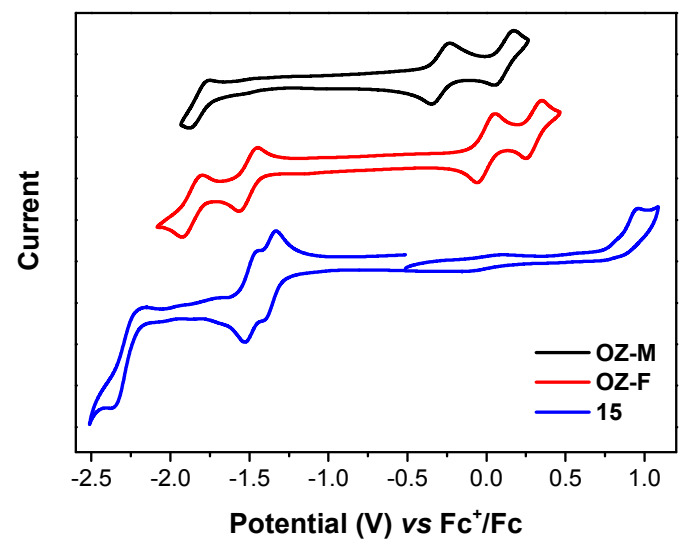

Figure 8. Cyclic voltammograms of $\mathbf{O Z}-\mathbf{M}, \mathbf{O Z}-\mathbf{F}$ and 15 in $\mathrm{DCM}$ with $0.1 \mathrm{M} \mathrm{Bu}_{4} \mathrm{NPF}_{6}$ as supporting electrolyte, $\mathrm{Ag} / \mathrm{Ag}^{+}$as reference electrode, Au disk as working electrode, Pt wire as counter electrode, and the scan rate at $50 \mathrm{mV} / \mathrm{s}$. The potential was externally calibrated by $\mathrm{Fc}^{+} / \mathrm{Fc}$ couple.

\section{CONCLUSIONS}

In summary, we have successfully developed a new synthetic method to synthesize the 2,6-NQDM bridged octazethrene derivatives and the 1,5-NQDM bridged octazethrene isomers. Our detailed experimental and theoretical studies demonstrate that the bridge structure has significant effect on their diradical character and consequently on the chemical reactivity and physical properties. The amphoteric redox behaviour and the ordered molecular packing of these new octazethrene derivatives make them promising candidates for ambipolar organic field-effect transistors and spin-dependent charge transport in the thin films and single crystals. The key intermediates $\mathbf{4}$ and $\mathbf{1 1}$ are expected to be very useful building blocks to access many quinoidal $\pi$-conjugated systems with significant diradical character. All these works are underway in our groups. 


\section{Experimental Section}

General Procedures. All reagents and starting materials were obtained from commercial suppliers and used without further purification. Dry toluene and dichloromethane were distilled under a nitrogen atmosphere over sodium and calcium hydride, respectively. The precusors 3,7-dibromonaphthalene-2,6-diol 1 and 1,5-dibromonaphthalene-2,6-diol 8 (Scheme 1) and (2(hexyloxy)naphthalen-1-yl)boronic acid were prepared according to the literature without further purification. ${ }^{9,16}$ Column chromatography was performed on silica gel $60(40-60 \mathrm{~nm}, 230-400 \mathrm{mesh})$. Melting points were measured on a standard melting point machine. All NMR spectra were recorded at commercial instruments $(300,500 \mathrm{MHz})$. All chemical shifts are quoted in ppm, relative to tetramethylsilane, using the residual solvent peak as a reference standard. Atmospheric Pressure Chemical Ionization (APCI MS) was performed on a commercial mass spectrometer. MALDI-TOF mass spectra were measured on a commercial instrument using tetracyanoquinodimethane (TCNQ) as a matrix. HRMS spectra were recorded using MALDI (TOF analyzer), ESI (TOF analyzer) and EI (Magnetic sector analyzer). UV-vis-NIR absorption was recorded on a commercial spectrophotometer. Cyclic voltammetry (CV) measurements were performed in dry DCM on a commerical instrument with a three-electrode cell, using $0.1 \mathrm{M} \mathrm{Bu}_{4} \mathrm{NPF}_{6}$ as supporting electrolyte, $\mathrm{AgCl} / \mathrm{Ag}$ as reference electrode, gold disk as working electrode, $\mathrm{Pt}$ wire as counter electrode, and scan rate at $50 \mathrm{mV} / \mathrm{s}$. The potential was externally calibrated against the ferrocene/ferrocenium couple. Continuous wave X-band ESR spectra were obtained with a commercial spectrometer using a variable temperature liquid nitrogen cryostat.

The femtosecond time-resolved transient absorption $(f s-\mathrm{TA})$ spectrometer consists of an optical parametric amplifier (OPA) pumped by a Ti:sapphire regenerative amplifier system operating at $1 \mathrm{kHz}$ repetition rate and an optical detection system. The generated OPA pulses have a pulse width of $\sim 100 \mathrm{fs}$ and an average power of $1 \mathrm{~mW}$ in the range of $280-2700 \mathrm{~nm}$, which are used as pump pulses. White light continuum (WLC) probe pulses were generated using a sapphire window (3 mm thick) by focusing a small portion of the fundamental $800 \mathrm{~nm}$ pulses which was picked off by a quartz plate before entering the OPA. The time delay between pump and probe beams was carefully controlled by making the pump beam travel along a variable optical delay. Intensities of the spectrally dispersed WLC probe pulses are monitored by a High Speed Spectrometer for both visible and near-infrared measurements. To obtain the time-resolved transient absorption difference signal $(\Delta \mathrm{A})$ at a specific time, the pump pulses were chopped at $500 \mathrm{~Hz}$ and absorption spectra intensities were saved alternately with or without pump pulse. Typically, 4000 pulses excite the samples to obtain the fs-TA spectra at each delay time. The polarization angle between pump and probe beam was set at the magic angle $\left(54.7^{\circ}\right)$ using a Glan-laser polarizer with a half-wave retarder in order to prevent polarization-dependent signals. Crosscorrelation fwhm in pump-probe experiments was less than $200 \mathrm{fs}$ and chirp of WLC probe pulses was measured to be $800 \mathrm{fs}$ in the 400-800 nm region. To minimize chirp, all reflection optics in the probe beam path and a quartz cell of 2 mm path length were used. After fs-TA experiments, the absorption spectra of all compounds were carefully examined to detect if there were artifacts due to degradation and photo-oxidation of samples. The three-dimensional data sets of $\Delta \mathrm{A}$ versus time and wavelength were sub- 
jected to singular value decomposition and global fitting to obtain the kinetic time constants and their associated spectra using Surface Xplorer software.

The two-photon absorption spectrum was measured in the NIR region using the open-aperture Z-scan method with 130 fs pulses from an optical parametric amplifier operating at a repetition rate of $1 \mathrm{kHz}$ generated from a Ti:sapphire regenerative amplifier system. After passing through a $10 \mathrm{~cm}$ focal length lens, the laser beam was focused and passed through a $1 \mathrm{~mm}$ quartz cell. Since the position of the sample cell could be controlled along the laser beam direction ( $z$ axis) using the motor controlled delay stage, the local power density within the sample cell could be simply controlled under constant laser intensity. The transmitted laser beam from the sample cell was then detected by the same photodiode as used for reference monitoring. The on-axis peak intensity of the incident pulses at the focal point, $I_{0}$, ranged from 40 to $60 \mathrm{GW} \mathrm{cm}^{-2}$. For a Gaussian beam profile, the nonlinear absorption coefficient can be obtained by curve fitting of the observed open-aperture traces $T(z)$ with Equation 1 and 2:

$$
T(z)=1-\frac{\beta I_{0}\left(1-e^{-\alpha_{0} l}\right)}{2 \alpha_{0}\left[1+\left(z / z_{0}\right)^{2}\right]}
$$

where $\alpha_{0}$ is the linear absorption coefficient, $l$ is the sample length, and $z_{0}$ is the diffraction length of the incident beam. After the nonlinear absorption coefficient has been obtained, the TPA cross section $\sigma^{(2)}$ of one solute molecule (in units of GM, where 1 GM $=10^{-50} \mathrm{~cm}^{4} \mathrm{~s}_{\text {photon }}{ }^{-1}$ molecule ${ }^{-1}$ ) can be determined by using the following relationship:

$$
\beta=\frac{10^{-3} \sigma^{(2)} N_{A} d}{h v}
$$

where $N_{\mathrm{A}}$ is the Avogadro constant, $d$ is the concentration of the compound in solution, $h$ is the Planck constant, and $v$ is the frequency of the incident laser beam.

Compound 2: Compound $1(3.17 \mathrm{~g}, 10.0 \mathrm{mmol})$ was added to the $\mathrm{NaH}(0.72 \mathrm{~g}, 30.0 \mathrm{mmol})$ suspension in $\mathrm{THF}$ at $0{ }^{\circ} \mathrm{C}$ under argon atmosphere. The mixture was string for 1 hour at room temperature and chloromethyl methyl ether $(2.26 \mathrm{ml}, 30 \mathrm{mmol})$ was added. After 12 hours the mixture was quenched by water and extracted with DCM. The organic layer was dried over anhydrous $\mathrm{MgSO}_{4}$. The solvent was removed under vacuum and the residue was purified by silica gel column chromatography using DCM/hexane (1/2, v/v) as eluent to give compound $2(3.65 \mathrm{~g}, 9.0 \mathrm{mmol})$ as a white solid in $90 \%$ yield, $\mathrm{mp} 148.4-150.6{ }^{\circ} \mathrm{C}$. ${ }^{1} \mathrm{H}$ NMR $\left(\mathrm{CDCl}_{3}, 300 \mathrm{MHz}\right): \delta 7.96(\mathrm{~s}, 2 \mathrm{H}), 7.34(\mathrm{~s}, 2 \mathrm{H}), 5.33(\mathrm{~s}, 4 \mathrm{H}), 3.55(\mathrm{~s}, 6 \mathrm{H}) ;{ }^{13} \mathrm{C} \mathrm{NMR}\left(\mathrm{CDCl}_{3}, 75 \mathrm{MHz}\right): \delta 150.5,131.2$, 129.8, 114.8, 110.0, 95.3, 56.3. HR-MS (EI): $m / z=403.9263$, calcd. for $\mathrm{C}_{14} \mathrm{H}_{14} \mathrm{Br}_{2} \mathrm{O}_{4}: \mathrm{m} / z=403.9253$, error $=2.47 \mathrm{ppm}$. 
Compound 3: To a solution of compound 2 (2.02 g, $5.0 \mathrm{mmol})$ in dry THF (100 mL) were dropwise added n-BuLi (5 ml, $2 \mathrm{M})$ at $78{ }^{\circ} \mathrm{C}$. The mixture was string for $1 \mathrm{~h}$ under this temperature, then dry dimethylformamide $(077 \mathrm{ml}, 10.0 \mathrm{mmol}) \mathrm{was}$ added in to the reaction mixture. After 12 hours the mixture was quenched by water and washed with water. The organic layer was extracted with DCM and dried over anhydrous $\mathrm{MgSO}_{4}$. The solvent was removed under vacuum and the residue was purified by silica gel column chromatography using DCM/hexane $(2 / 1, \mathrm{v} / \mathrm{v})$ as eluent to give compound $3(0.98 \mathrm{~g}, 3.25 \mathrm{mmol})$ as a yellow solid in $65 \%$ yield, mp 160.0-162.1 ${ }^{\circ} \mathrm{C} .{ }^{1} \mathrm{H} \mathrm{NMR}\left(\mathrm{CDCl}_{3}, 300 \mathrm{MHz}\right): \delta 10.16(\mathrm{~s}, 2 \mathrm{H}), 8.29(\mathrm{~s}, 2 \mathrm{H}), 7.59(\mathrm{~s}, 2 \mathrm{H}), 5.39(\mathrm{~s}, 4 \mathrm{H}), 3.56(\mathrm{~s}, 6 \mathrm{H}) ;{ }^{13} \mathrm{C} \mathrm{NMR}$ $\left(\mathrm{CDCl}_{3}, 75 \mathrm{MHz}\right): \delta 189.8,154.3,131.9,129.1,128.0,112.1,95.0,56.5 . \mathrm{HR}-\mathrm{MS}(\mathrm{EI}): \mathrm{m} / z=304.0947$, calcd. for $\mathrm{C}_{16} \mathrm{H}_{16} \mathrm{O}_{6}: m / z=$ 304.0941, error $=1.93 \mathrm{ppm}$.

Compound 4: To a solution of compound 3 (2.02 g, $5.0 \mathrm{mmol})$ in dry THF (50 mL) were added concentrated $\mathrm{HCl}(3.0 \mathrm{ml})$. The mixture was heated to refluxing for $5 \mathrm{~h}$. After cooling to the room temperature the solvent was evaporated and the solid was washed with water and methanol. The crude product was dissolved in $100 \mathrm{ml} \mathrm{DCM}$ with pyridine $(1.0 \mathrm{ml})$ and cooled to the $0{ }^{\circ} \mathrm{C}$. Trifluoromethanesulfonic anhydride $(10.0 \mathrm{mmol}, 2.0 \mathrm{eq})$ was added to the reaction mixture under this temperature and then the mixture was allowed to warm to the room temperature and stirred for further 1 hour. The mixture was quenched by water and washed with $2 \mathrm{M} \mathrm{HCl}$ solution and water. The organic layer was extracted with $\mathrm{DCM}$ and dried over anhydrous $\mathrm{MgSO}_{4}$. The solvent was removed under vacuum and the residue was purified by silica gel column chromatography using DCM/hexane (4/1, v/v) as eluent to give compound $4(2.04 \mathrm{~g}, 4.25 \mathrm{mmol})$ as a light yellow solid in $85 \%$ yield, $\mathrm{mp} 179.0-182.0{ }^{\circ} \mathrm{C} .{ }^{1} \mathrm{H} \mathrm{NMR}^{\mathrm{N}}\left(\mathrm{CDCl}{ }_{3}, 300\right.$ $\mathrm{MHz}): \delta 10.40(\mathrm{~s}, 2 \mathrm{H}), 8.61(\mathrm{~s}, 2 \mathrm{H}), 8.09(\mathrm{~s}, 2 \mathrm{H}) ;{ }^{13} \mathrm{C} \mathrm{NMR}\left(\mathrm{CDCl}_{3}, 75 \mathrm{MHz}\right): \delta 185.8(\mathrm{C}=\mathrm{O}), 146.8,133.86,133.70,129.6,122.7$, 120.8, 116.6. HR-MS (EI): $m / z=479.9417$, calcd. for $\mathrm{C}_{14} \mathrm{H}_{6} \mathrm{~F}_{6} \mathrm{O}_{8} \mathrm{~S}_{2}: m / z=479.9403$, error $=3.01 \mathrm{ppm}$.

Compound 5: A mixture of compound 4 (0.48 g, 1 mmol), (2-(hexyloxy)naphthalen-1-yl)boronic acid (0.82 g, 3 mmol), $\mathrm{Pd}\left(\mathrm{PPh}_{3}\right)_{4}(58 \mathrm{mg}, 0.05 \mathrm{mmol})$ in toluene $(25 \mathrm{~mL})$, ethanol $\left.(3 \mathrm{~mL})\right)$ and $\mathrm{K}_{2} \mathrm{CO}_{3}$ aqueous solution $(2 \mathrm{M}, 3 \mathrm{~mL})$ was degassed by three freeze-pump-thaw cycles. The reaction mixture was heated at $105{ }^{\circ} \mathrm{C}$ overnight under nitrogen. After cooling to the room temperature, the mixture was washed with water and extracted with DCM. The organic layer was dried over anhydrous $\mathrm{MgSO}_{4}$. The solvent was removed under vacuum and the residue was purified by silica gel column chromatography using DCM/hexane (1/1, $\mathrm{v} / \mathrm{v})$ as eluent to give compound $5(0.57 \mathrm{~g}, 0.90 \mathrm{mmol})$ as a yellow solid in $90 \%$ yield, $\mathrm{mp}>350{ }^{\circ} \mathrm{C} .{ }^{1} \mathrm{H} \mathrm{NMR}\left(\mathrm{CDCl}{ }_{3}, 300 \mathrm{MHz}\right) \delta$ ppm: $9.82(\mathrm{~s}, 2 \mathrm{H}), 8.68(\mathrm{~s}, 2 \mathrm{H}), 8.11(\mathrm{~s}, 2 \mathrm{H}), 8.01(\mathrm{~d}, J=9.0 \mathrm{~Hz}, 2 \mathrm{H}), 7.93-7.90(\mathrm{~m}, 2 \mathrm{H}), 7.53-7.50$ (m, 2H), 7.44-7.39 (m, 6H), 4.12-4.04 (m, 4H), 1.64-1.56(m, 4H), $1.15(\mathrm{br}, 12 \mathrm{H}), 0.76(\mathrm{t}, J=6 \mathrm{~Hz}, 6 \mathrm{H}) .{ }^{13} \mathrm{C} \mathrm{NMR}\left(\mathrm{CDCl}_{3}, 75 \mathrm{MHz}\right) \delta \mathrm{ppm}: 192.5(\mathrm{C}=\mathrm{O})$, $153.89,153.84,135.9,135.0,134.9,134.4,134.3,133.9,133.4,129.1,128.2,128.1,127.0,124.7,123.8,120.0,119.8,114.0$, 113.9, 31.2, 31.1, 29.11, 29.02, 25.3, 22.3, 13.7. HR-MS (EI): $m / z=636.3233$, calcd. for $\mathrm{C}_{44} \mathrm{H}_{44} \mathrm{O}_{4}: m / z=636.3244$, error $=-0.17$ ppm. 
Compound OZ-M: Mesitylmagnesium $(1.0 \mathrm{M}, 1.0 \mathrm{~mL})$ was added to the $15 \mathrm{~mL}$ dry THF solution of compound $5(0.06 \mathrm{~g}, 0.10$ mmol) under argon atmosphere, the mixture was stirred at room temperature for 8 hours. The reaction mixture was quenched by water and extracted by chloroform. The organic layer was dried over $\mathrm{Na}_{2} \mathrm{SO}_{4}$ and the solvent was removed under reduced pressure. The crude compound 6 was then dissolved in $20 \mathrm{~mL}$ dry DCM under argon atmosphere and $0.2 \mathrm{~mL}$ of $\mathrm{BF}_{3} \cdot \mathrm{OEt}_{2}$ was added. The mixture was stirred for 5 minutes and quenched by methanol. The solvent was removed under reduced pressure. DDQ $(0.0227 \mathrm{~g}$, $0.1 \mathrm{mmol}$ ) was added dropwise to the $20 \mathrm{~mL}$ dry toluene solution of compound 7. Upon addition of DDQ solution, the color of the reaction mixture changed slowly from light blue to dark green, and the reaction was monitored by TLC until completion. After evaporation of the solvent, the residue was purified by column chromatography (silica gel, DCM/hexane (1/3, v/v) as eluent) to give compound OZ-M (37 mg, $45 \%$ in three steps) as a black solid, decomposed at $217.9{ }^{\circ} \mathrm{C}$. HR-MS (ESI): $\mathrm{m} / \mathrm{z}=838.4768$, calcd. for $\mathrm{C}_{62} \mathrm{H}_{62} \mathrm{O}_{2}: m / z=838.4744$, error $=-2.8 \mathrm{ppm}$.

Compound OZ-F: Starting with compound $5(60 \mathrm{mg}, 0.10 \mathrm{mmol})$ following the similar procuduce to compound OZ-M could gave compound OZ-F (37 mg, $0.04 \mathrm{mmol}$ ) as a black solid in $40 \%$ yield, decomposed at $271.5^{\circ} \mathrm{C}$. HR-MS (ESI): $\mathrm{m} / z=935.2937$, calcd. for $\mathrm{C}_{56} \mathrm{H}_{41} \mathrm{~F}_{10} \mathrm{O}_{2}[\mathrm{M}+1]^{+}: m / z=935.2941$, error $=0.5 \mathrm{ppm}$.

Compound 9: Starting with 1,5-dibromonaphthalene-2,6-diol (3.17 g, $10.0 \mathrm{mmol})$ and following the similar procedure to compound 2, compound $9(3.40 \mathrm{~g}, 8.50 \mathrm{mmol})$ was obtained as a white solid in $85 \%$ yield, mp 102.4-103.9 ${ }^{\circ} \mathrm{C} .{ }^{1} \mathrm{H} \mathrm{NMR}\left(\mathrm{CDCl}_{3}, 300\right.$ MHz): $\delta 8.23(\mathrm{~d}, J=9 \mathrm{~Hz}, 2 \mathrm{H}), 7.50(\mathrm{~d}, J=9 \mathrm{~Hz}, 2 \mathrm{H}), 5.35(\mathrm{~s}, 4 \mathrm{H}), 3.57(\mathrm{~s}, 6 \mathrm{H}) ;{ }^{13} \mathrm{C} \mathrm{NMR}\left(\mathrm{CDCl}_{3}, 75 \mathrm{MHz}\right): \delta 151.0,129.8$, 127.4, 118.4, 110.4, 95.6, 56.5. HR-MS (EI): $m / z=403.9251$, calcd. for $\mathrm{C}_{14} \mathrm{H}_{14} \mathrm{Br}_{2} \mathrm{O}_{4}: m / z=403.9253$, error $=-0.44$ ppm.

Compound 10: Start with compound $9(4.0 \mathrm{~g}, 10.0 \mathrm{mmol})$ following the similar procedure to compound 3, compound 10 (1.77 $\mathrm{g}$, $5.9 \mathrm{mmol})$ was obtained as a yellow solid in 59\% yield, mp 135.5-137.0 ${ }^{\circ} \mathrm{C} .{ }^{1} \mathrm{H}$ NMR $\left(\mathrm{CDCl}_{3}, 300 \mathrm{MHz}\right): \delta 10.90(\mathrm{~s}, 2 \mathrm{H}), 9.52(\mathrm{~d}$, $J=12 \mathrm{~Hz}, 2 \mathrm{H}), 7.59(\mathrm{~d}, J=12 \mathrm{~Hz}, 2 \mathrm{H}), 5.40(\mathrm{~s}, 4 \mathrm{H}), 3.56(\mathrm{~s}, 6 \mathrm{H}) ;{ }^{13} \mathrm{C}$ NMR $\left(\mathrm{CDCl}_{3}, 75 \mathrm{MHz}\right): \delta 192.0(\mathrm{C}=\mathrm{O}), 160.6,134.1$, 127.1, 118.6, 117.4, 95.1, 56.7. HR-MS (EI): $\mathrm{m} / z=304.0946$, calcd. for $\mathrm{C}_{16} \mathrm{H}_{16} \mathrm{O}_{6}: \mathrm{m} / z=304.0941$, error $=1.53 \mathrm{ppm}$.

Compound 11: Start with compound $10(1.52 \mathrm{~g}, 5.0 \mathrm{mmol})$ following the similar procedure to compound 4, compound $11(2.16 \mathrm{~g}$, $4.5 \mathrm{mmol})$ was obtained as a yellow solid in $90 \%$ yield, mp $128.5-130.0{ }^{\circ} \mathrm{C} .{ }^{1} \mathrm{H} \mathrm{NMR}\left(\mathrm{CDCl}_{3}, 300 \mathrm{MHz}\right): \delta 10.90(\mathrm{~s}, 2 \mathrm{H}), 9.66(\mathrm{~d}$, $J=9 \mathrm{~Hz}, 2 \mathrm{H}), 7.77(\mathrm{~d}, J=9 \mathrm{~Hz}, 2 \mathrm{H}) ;{ }^{13} \mathrm{C} \mathrm{NMR}\left(\mathrm{CDCl}_{3}, 75 \mathrm{MHz}\right): \delta 187.8(\mathrm{C}=\mathrm{O}), 152.5,134.9,130.5,123.9,122.6,120.6,116.4$. HR-MS (EI): $m / z=479.9414$, calcd. for $\mathrm{C}_{14} \mathrm{H}_{6} \mathrm{~F}_{6} \mathrm{O}_{8} \mathrm{~S}_{2}: m / z=479.9403$, error $=2.37 \mathrm{ppm}$.

Compound 12: Start with compound $11(0.48 \mathrm{~g}, 1.0 \mathrm{mmol})$ following the similar procedure to compound 5, compound $12(0.58 \mathrm{~g}$, $0.91 \mathrm{mmol})$ was obtained as a yellow solid in $91 \%$ yield, $\mathrm{mp}>350{ }^{\circ} \mathrm{C} .{ }^{1} \mathrm{H}$ NMR $\left(\mathrm{CDCl}_{3}, 300 \mathrm{MHz}\right): \delta 10.11(\mathrm{~s}, 2 \mathrm{H}), 9.77-9.73(\mathrm{~m}$, 2H), $7.99(\mathrm{~d}, J=9 \mathrm{~Hz}, 2 \mathrm{H}), 7.92-7.88(\mathrm{~m}, 2 \mathrm{H}), 7.66(\mathrm{~d}, J=9 \mathrm{~Hz}, 2 \mathrm{H}), 7.41-7.32(\mathrm{~m}, 8 \mathrm{H}), 4.13-4.04(\mathrm{~m}, 4 \mathrm{H}), 1.62-1.58(\mathrm{~m}, 4 \mathrm{H})$, 
1.21-1.14 (m, 12H), 0.79-0.74 (m, 6H); ${ }^{13} \mathrm{C} \mathrm{NMR}\left(\mathrm{CDCl}_{3}, 75 \mathrm{MHz}\right): \delta \mathrm{ppm} 195.2(\mathrm{C}=\mathrm{O}), 154.0,153.9,144.1,144.0,133.8,133.6$, $132.84,132.80,131.83,131.80,130.69,130.65,130.5,129.58,129.51,128.9,128.8,128.1,127.14,127.10,125.0,124.9,123.93$, $123.90,120.8,120.7,114.2,114.1,69.4,69.3,31.29,31.21,29.1,29.0,25.4,25.3,22.4,22.3,13.85,13.80 . \mathrm{HR}-\mathrm{MS}(\mathrm{EI}): m / z=$ 636.3232, calcd. for $\mathrm{C}_{44} \mathrm{H}_{44} \mathrm{O}_{4}: m / z=636.3234$, error $=-0.34 \mathrm{ppm}$.

\begin{abstract}
Compound 15: Following the similar procedure to compound 7, oxidation precursor compound $\mathbf{1 4}$ was obtained as a yellow solid. DDQ (1 eq) was added dropwise to the $20 \mathrm{~mL}$ dry toluene solution of compound 14 (84.1 mg, $0.10 \mathrm{mmol})$. Upon addition of DDQ solution, the color of the reaction mixture changed quickly from light yellow to dark green, then the color changed to dark red over 1 hour under the argon. After evaporation of the solvent, the residue was purified by column chromatography (silica gel, hexane/ethyl acetate $(4 / 1, \mathrm{v} / \mathrm{v})$ as eluent) to give compound $\mathbf{1 5}(21.4 \mathrm{mg}, 0.03 \mathrm{mmol})$ as a red-black solid in $32 \%$ yield, $\mathrm{mp}>350{ }^{\circ} \mathrm{C}$. ${ }^{1} \mathrm{H}$ NMR (d d $\left.\mathrm{THF}, 500 \mathrm{MHz}\right): \delta \mathrm{ppm} 9.82(\mathrm{~d}, J=10 \mathrm{~Hz}, 2 \mathrm{H}), 8.07$ (d, $\left.J=10 \mathrm{~Hz}, 2 \mathrm{H}\right), 7.95$ (d, $\left.J=5 \mathrm{~Hz}, 2 \mathrm{H}\right), 7.86(\mathrm{~d}, J=10 \mathrm{~Hz}$, 2H), $7.74(\mathrm{~d}, J=10 \mathrm{~Hz}, 2 \mathrm{H}), 7.55-7.52(\mathrm{~m}, 2 \mathrm{H}), 7.14(\mathrm{~s}, 4 \mathrm{H}), 6.75(\mathrm{~d}, J=10 \mathrm{~Hz}, 2 \mathrm{H}), 2.48(\mathrm{~s}, 6 \mathrm{H}), 1.69(\mathrm{~s}, 12 \mathrm{H}) ;{ }^{13} \mathrm{C} \mathrm{NMR}\left(\mathrm{d}_{8^{-}}\right.$ THF, $75 \mathrm{MHz}): \delta$ ppm $184.9(\mathrm{C}=\mathrm{O}), 143.5,136.5,136.4,135.3,134.2,131.9,130.5,129.4,128.6,128.48,128.40,127.4,127.3$, 126.6, 126.5, 125.7, 124.1, 122.0, 119.7, 27.7,18.4, 17.6. HR-MS (ESI): $m / z=669.2792$, calcd. for $\mathrm{C}_{50} \mathrm{H}_{37} \mathrm{O}_{2}[\mathrm{M}+1]^{+}: m / z=$ 669.2788, error $=-0.5 \mathrm{ppm}$.
\end{abstract}

\title{
ASSOCIATED CONTENT
}

Supporting Information. X-ray crystallography (CIF files), additional physical characterization data and theoretical calculations are in supporting information. This material is available free of charge via the Internet at http://pubs.acs.org

\section{Corresponding Authors}

chmwuj@nus.edu.sg; dongho@yonsei.ac.kr; msedingj@nus.edu.sg

\section{ACKNOWLEDGMENT}

J. W. acknowledges the financial support from the MOE Tier 3 Programme (MOE2014-T3-1-004), Tier 2 grant (MOE2014-T2-1080) and A*STAR JCO grant (1431AFG100). This work at Yonsei University was supported by the Global Frontier R\&D Program on Center for Multiscale Energy System funded by the National Research Foundation under the Ministry of Science, ICT \& Future, Korea (NRF-2014M3A6A7060583). We thank Dr. Tan Geok Kheng and Dr. Bruno Donnadieu for the crystallographic analysis.

\section{REFERENCES}

1 (a) Sun, Z.; Zeng, Z.; Wu, J. Acc. Chem. Res. 2014, 47, 2582-2591; (b) Kubo, T. Chem. Lett. 2015, 44, 111-122; (c) Zeng, Z.; Shi, X.; Chi, C.; López Navarrete, J. T.; Casado, J.; Wu, J. Chem. Soc. Rev. 2015, 44, 6578-6596.

2 (a) Chase, D. T.; Rose, B. D.; McClintock, S. P.; Zakharov, L. N.; Haley, M. M. Angew. Chem. Int. Ed. 2011, 50, 1127-1130; (b) Shimizu, A.; Tobe, Y. Angew. Chem. Int. Ed. 2011, 50, 6906-6910; (c) Fix, A. G.; Chase, D. T.; Haley, M. M. Top. Curr. Chem. 
2012 , 69, 890-911; (d) Fix, A. G.; Deal, P. E.; Vonnegut, C. L.; Rose, B. D.; Zakharov, L. N.; Haley, M. M. Org. Lett. 2013, 15, 1362-1365; (e) Rose, B. D.; Vonnegut, C. L.; Zakharov, L. N.; Haley, M. M. Org. Lett. 2013, 14, 2426-2429; (f) Shimizu, A.; Kishi, R.; Nakano, M.; Shiomi, D.; Sato, K.; Takui, T.; Hisaki, I.; Miyata, M.; Tobe, Y. Angew. Chem. Int. Ed. 2013, 52, 6076-6079; (g) Miyoshi, H.; Nobusue, S.; Shimizu, A.; Hisaki, I.; Miyatab, M.; Tobe, Y. Chem. Sci. 2014, 5, 163-168; (h) Young, B. S.; Chase, D. T.; Marshall, J. L.; Vonnegut, C. L.; Zakharov, L. N.; Haley, M. M. Chem. Sci. 2014, 5, 1008-1014; (i) Shimizu, A.; Nobusue, S.; Miyoshi, H.; Tobe, Y. Pure Appl. Chem. 2014, 86, 517-528.

3 (a) Ohashi, K.; Kubo, T.; Masui, T.; Yamamoto, K.; Nakasuji, K.; Takui, T.; Kai, Y.; Murata, I. J. Am. Chem. Soc. 1998, 120, 2018-2027; (b) Kubo, T.; Sakamoto, M.; Akabane, M.; Fujiwara, Y.; Yamamoto, K.; Akita, M.; Inoue, K.; Takui T.; Nakasuji, K. Angew. Chem. Int. Ed. 2004, 43, 6474-6479; (c) Kubo, T.; Shimizu, A.; Sakamoto, M.; Uruichi, M.; Yakushi, K.; Nakano, M.; Shiomi, D.; Sato, K.; Takui, T.; Morita Y.; Nakasuji, K. Angew. Chem. Int. Ed. 2005, 44, 6564-6568; (d) Kubo, T.; Shimizu, A.; Uruichi, M.; Yakushi, K.; Nakano, M.; Shiomi, D.; Sato, K.; Takui T.; Morita,Y.; Nakasuji, K. Org. Lett. 2007, 9, 81-84. (e) Shimizu, A.; Uruichi, M.; Yakushi, K.; Matsuzaki, H.; Okamoto, H.; Nakano, M.; Hirao, Y.; Matsumoto, K.; Kurata H.; Kubo, T. Angew. Chem. Int. Ed. 2009, 48, 5482-5486; (f) Shimizu, A.; Kubo, T.; Uruichi, M.; Yakushi, K.; Nakano, M.; Shiomi, D.; Sato, K.; Takui, T.; Hirao, Y.; Matsumoto, K.; Kurata, H.; Morita Y.; Nakasuji, K. J. Am. Chem. Soc. 2010, 132, 14421-14428; (g) Shimizu, A.; Hirao, Y.; Matsumoto, K.; Kurata, H.; Kubo, T.; Uruichi, M.; Yakushi, K. Chem. Commun. 2012, 48, 5629-5631.

4 (a) Umeda, R.; Hibi, D.; Miki, K.; Tobe, Y. Org. Lett. 2009, 11, 4104-4106; (b) Sun, Z.; Huang, K.-W.; Wu, J. J. Am. Chem. Soc. 2011, 133, 11896-11899; (c) Li, Y.; Heng, K.-W.; Lee, B. S.; Aratani, N.; Zafra, J. L.; Bao, N.; Lee, R.; Sung, Y. M.; Sun, Z.; Huang, K.-W.; Webster, R. D.; López Navarrete, J. T.; Kim, D.; Osuka, A.; Casado, J.; Ding, J.; Wu, J. J. Am. Chem. Soc. 2012, 134, 14913-14922; (d) Hu, P.; Lee, S.; Herng, T. S.; Aratani, N.; Gonçalves, T. P.; Qi, Q.; Shi, X.; Yamada, H.; Huang, K.-W.; Ding, J.; Kim, D.; Wu, J. J. Am. Chem. Soc. 2016, 134, 1065-1077; (e) Ni, Y.; Lee, S.; Son, M.; Aratani, N.; Ishida, M.; Yamada, H.; Chang, Y.-T.; Furuta, H.; Kim, D.; Wu, J. Angew. Chem. Int. Ed. 2016, 55, 2815-2819.

5 (a) Konishi, A.; Hirao, Y.; Nakano, M.; Shimizu, A.; Botek, E.; Champagne, B.; Shiomi, D.; Sato, K.; Takui, T.; Matsumoto, K.; Kurata, H.; Kubo, T. J. Am. Chem. Soc. 2010, 132, 11021-11023; (b) Konishi, A.; Hirao, Y.; Matsumoto, K.; Kurata, H.; Kishi, R.; Shigeta, Y.; Nakano, M.; Tokunaga, K.; Kamada, K.; Kubo, T. J. Am. Chem. Soc. 2013, 135, 1430-1437.

6 (a) Zeng, Z.; Ishida, M.; Zafra, J. L.; Zhu, X.; Sung, Y. M.; Bao, N.; Webster, R. D.; Lee, B. S.; Li, R.-W.; Zeng, W.; Li, Y.; Chi, C.; López Navarrete, J. T.; Ding, J.; Casado, J.; Kim D.; Wu, J. J. Am. Chem. Soc. 2013, 135, 6363-6371; (b) Zeng, Z.; Lee, S.; Zafra, J. L.; Ishida, M.; Zhu, X.; Sun, Z.; Ni, Y.; Webster, R. D.; Li, R.-W.; López Navarrete, J. T.; Chi, C.; Ding, J.; Casado, J.; Kim, D.; Wu, J. Angew. Chem. Int. Ed. 2013, 52, 8561-8565; (c) Zeng, Z.; Lee, S.; Son, M.; Fukuda, K.; Burrezo, P. M.; Zhu, X.; Qi, Q.; Li, R.-W.; López Navarrete, J. T.; Ding, J.; Casado, J.; Nakano, M.; Kim D.; Wu, J. J. Am. Chem. Soc. $2015,137,8572-8583$.

7. Luo, D.; Lee, S.; Zheng, B.; Sun, Z.; Zeng, W.; Huang, K.-W.; Furukawa, K.; Kim, D.; Webster, R. D.; Wu, J. Chem. Sci. 2014, 
$5,4944-4952$.

8. Li, Y.; Huang, K.-W.; Sun, Z.; Webster, R. D.; Zeng, Z.; Zeng, W.; Chi, C.; Furukawa, K.; Wu, J. Chem. Sci. 2014, 5, 19081914.

9. Cammidge, A. N.; Goddard, H. M.; Schubert, P. J.; Gopee, H.; Hughes, D. L.; Gonzalez-Lucas, D. Org. Lett. 2011, 13, 60346037.

10. Bleaney, B.; Bowers, K. D. Proc. R. Soc. London Ser. A 1952, 214, 451-453.

11. Crystallographic data for OZ-M: $\mathrm{C}_{62} \mathrm{H}_{62} \mathrm{O}_{2}, M_{\mathrm{w}}=838.47$; Monoclinic; space group P 2(1)/c; $a=8.3105(3) \AA, b=9.6129(3) \AA$, $c=28.8543(10) \AA, \alpha=90^{\circ}, \beta=96.657(2)^{\circ}, \gamma=90^{\circ} ; \mathrm{V}=2289.57(14) \AA^{3} ; Z=4 ; \rho_{\text {calcd }}=1.217 \mathrm{Mg} / \mathrm{m}^{3} ; R_{1}=0.0464(\mathrm{I}>2 \sigma(\mathrm{I})), w R_{2}=$ 0.1148 (all data). CCDC No.: 1418608. Crystallographic data for OZ-F: $\mathrm{C}_{63} \mathrm{H}_{48} \mathrm{~F}_{10} \mathrm{O}_{2}, M_{\mathrm{w}}=1027.01$; triclinic; space group P-1; $a=$ $9.2006(4) \AA, b=10.9573(6) \AA, c=13.7554(6) \AA, \alpha=95.316(2)^{\circ}, \beta=99.2040(10)^{\circ}, \gamma=114.8070(10)^{\circ} ; V=1222.66(10) \AA^{3} ; Z=1$; $\rho_{\text {calcd }}=1.395 \mathrm{Mg} / \mathrm{m}^{3} ; R_{1}=0.0529(\mathrm{I}>2 \sigma(\mathrm{I})), w R_{2}=0.1467$ (all data). CCDC No.: 1419168 .

12. Fallah-Bagher-Shaidaei, H.; Wannere, C. S.; Corminboeuf, C.; Puchta, R.; Schleyer, P. v. R. Org. Lett. $2006,8,863-866$.

13. Crystallographic data for 15: $\mathrm{C}_{50} \mathrm{H}_{36} \mathrm{O}_{2}, M_{\mathrm{w}}=669.28$; Monoclinic; space group P 21/n; $a=11.2442(6) \AA, b=12.6155(7) \AA, c$ $=11.9818(7) \AA, \alpha=90^{\circ}, \beta=92.599(3)^{\circ}, \gamma=90^{\circ} ; V=1697.88(16) \AA^{3} ; Z=4 ; \rho_{\text {calcd }}=1.308 \mathrm{Mg} / \mathrm{m}^{3} ; R_{1}=0.0413(\mathrm{I}>2 \sigma(\mathrm{I})), w R_{2}=$ 0.1300 (all data). CCDC No.: 1419168.

14. Motta, S. D.; Negri, F.; Fazzi, D.; Castiglioni, C.; Canesi, E. V. J. Phys. Chem. Lett. 2010, 1, 3334-3339.

15. (a) Nakano, M.; Nagao, H.; Yamaguchi, K. Phys. Rev. A 1997, 55, 1503-1513; (b) Nakano, M.; Kishi, R.; Nitta, T.; Kubo, T.; Nakasuji, K.; Kamada, K.; Ohta, K.; Champagne, B.; Botek, E.; Yamaguchi, K. J. Phys. Chem. A 2005, 109, 885-891; (c) Nakano, M.; Kubo, T.; Kamada, K.; Ohta, K.; Kishi, R.; Ohta, S.; Nakagawa, N.; Takahashi, H.; Furukawa, S.; Morita, Y.; Nakasuji, K.; Yamaguchi, K. Chem. Phys. Lett. 2006, 418, 142; (d) Ohta, S.; Nakano, M.; Kubo, K.; Kamada, K.; Ohta, K.; Kishi, R.; Nakagawa, N.; Champagne, B.; Botek, E.; Takebe, A.; Umezaki, S.; Nate, M.; Takahashi, H.; Furukawa, S.; Morita, Y.; Nakasuji, K.; Yamaguchi, K. J. Phys. Chem. A 2007, 111, 3633-3641; (e) Nakano, M.; Kishi, R.; Takebe, A.; Nate, M.; Takahashi, H.; Kubo, T.; Kamada, K.; Ohta, K.; Champagne, B.; Botek, E. Comput. Lett. 2007, 3, 333-338; (f) Kamada, K.; Ohta, K.; Kubo, T.; Shimizu, A.; Morita, Y.; Nakasuji, K.; Kishi, R.; Ohta, S.; Furukawa, S. I.; Takahashi, H.; Nakano, M. Angew. Chem. Int. Ed. 2007, 46, 3544-3546; (g) Nakano, M.; Kishi, R.; Ohta, S.; Takahashi, H.; Kubo, T.; Kamada, K.; Ohta, K.; Botek, E.; Champagne, B. Phys. Rev. Lett. 2007, 99, 033001-033004.

16. Osaka, I.; Shinamura, S.; Abe, T.; Takimiya, K. J. Mater. Chem. C 2013, 1, 1297-1304. 